\title{
Kyoto agreement creates new agenda for climate research
}

[кYото] Last week's adoption of the 'Kyoto protocol' on climate change has been welcomed by climate scientists as "a step in the right direction" as they prepare to respond to the challenges arising from the conference.

Having already played an important role in the run-up to the protocol's adoption, the scientific advisory bodies to the conference have been asked to provide solutions to two immediate challenges.

First, scientists need to lay out in detail how greenhouse gas emissions are to be measured and verified - including the release and absorption of carbon from changes in land use and forest management. Second, scientists have been asked to come up with a mechanism for 'trading' emissions before the next climate conference in Buenos Aires in a year's time.

After ratification by at least 55 countries, the protocol will require developed countries to reduce emissions of a combined 'basket' of six gases by an average of 5.2 per cent from their 1990 levels between 2008 and 2012. Gases will be calculated from both their sources and 'sinks'. There are no commitments - voluntary or otherwise - for developing countries.

Most of the 39 developed countries covered by the protocol will reduce emissions by 8 per cent. The United States will have to

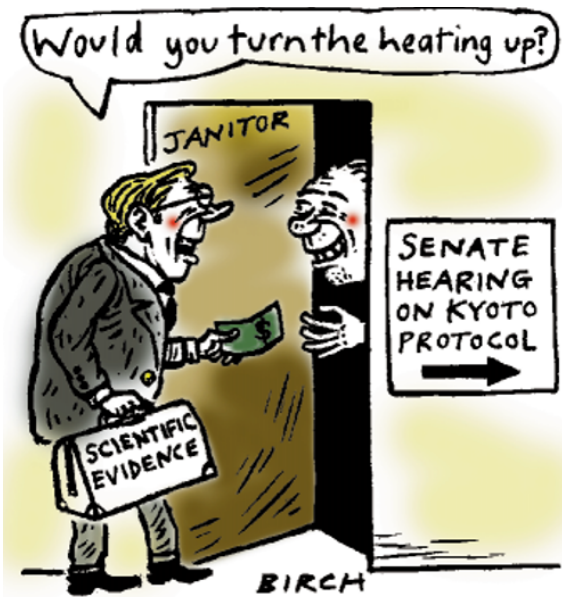

reduce emissions by 7 per cent, and Japan by 6 per cent. Russia, New Zealand and the Ukraine will be allowed to stabilize emissions at 1990 levels. Australia will be allowed to raise its emissions by 8 per cent above 1990 levels.

Reductions to three gases - carbon dioxide, methane and nitrous oxide — will be made relative to 1990 levels. Countries can choose whether to use 1990 levels or a 1995 baseline when reducing emissions of the other three gases: hydrofluorocarbons, perfluorocarbons, and sulphur hexafluoride.

Reducing a combination of gases poses governments with a difficulty, as the relative impact of the different gases is not the same: one tonne of carbon dioxide does not affect climate in the same way as one tonne of methane, so the quantities of each country's emissions of each gas cannot be added in a linear fashion.

One of the most controversial parts of the protocol allows higher-emitting developed countries to achieve their reduction targets by buying emissions 'credits' from lower polluting developed countries under a scheme known as emissions trading (see Briefing, Nature 390, 215; 1997).

A similar scheme - known as joint implementation — will allow higher polluting countries to obtain emissions credits by building 'clean' technology projects in lower polluting developed countries. The United States will achieve some of its target by buying credits from Russia and the Ukraine, whose emissions are already below 1990 levels.

Competing schemes for emissions trading have already been developed by the World Bank (see Nature 390, 7; 1997) and the United Nations Conference on Trade and Development. Frank Joshua, head of greenhouse emissions trading at UNCTAD, believes that the details of a practical trading mechanism will not take long to work out.

In contrast, research into calculating the quantity of greenhouse gases released from

\section{Battling for science takes its toll on UN climate panel stalwarts}

[куото] A leading climate scientist is to leave the United Nations' expert panel, and a second is considering his future with the body. Both had been at the centre of attempts last year by US energy lobbyists to discredit the panel's conclusion that human activities are warming the planet.

Tom Wigley, a senior scientist at the National Center for Atmospheric Research in Boulder, Colorado, has decided he will no longer take part in the work of the Intergovernmental Panel on Climate Change (IPCC), which periodically reviews the world's climate change research.

His colleague Ben Santer, an atmospheric physicist at the Lawrence Livermore National Laboratory in California, says he has yet to decide whether to return to the IPCC. Santer was the main focus of a campaign last year to discredit the science of climate change (see Nature 381, 195; 1997).

Wigley says he feels his time is better spent "doing science, rather than reviewing it". Scientists spend too long on the review process, he says, when they should be involved in research that will help to "prove conclusively that there is anthropogenic climate change".

Santer says a part of him now wants to steer clear of the IPCC. "It has been tremendously distressing and destroyed my family." He says that the IPCC may be better off by choosing another scientist not connected with the previous report. But he says he has learnt much from the experience of writing a report with political implications, and will not repeat his mistakes if given a second chance.

The latest IPCC report concludes that the "balance of evidence" suggests that human activity is warming the planet, and formed the basis of the Kyoto protocol agreed last week (see above). But opponents of the protocol have used the apparent discrepancy in the fact that the degree of warming from surface data is greater than that from satellite instruments to argue for a delay in action to slow down man-made climate change.

This discrepancy seems likely to continue to be used in attempts to block or delay the protocol's ratification in the US Senate, and Wigley says that finding the reasons for it should now be a priority.

Both Wigley and Santer are also critical of a recent IPCC decision to appoint 'review editors' to liaise between scientists and authors of research, and to sign-off reports after they have been peer reviewed. Wigley says this will increase the time spent on reviews, and may deter people from volunteering to take part in the IPCC process. Santer says it will turn the task of being an IPCC author "into a full-time job".

Sir John Houghton, chairman of IPCC's science working group, is sympathetic to Wigley's decison not to be part of the IPCC. But he says that the IPCC process is important in bringing scientists together, and focusing ideas and resources on specific problems. "I hope we will continue to get leading scientists," he says. "If they get disillusioned with the IPCC process, then the quality of the reports goes down. That will be bad for science and for policy." Ehsan Masood 
changes in land use, rice cultivation, and the clearing of forests is still in relative infancy. Most scientists did not expect these sources of emissions to be included in a protocol.

One of the first tasks - which began at a meeting of climate scientists last month will be to 'balance' the Earth's carbon budget. At present, there is a discrepancy between the combined inventory of carbon emissions and the quantity of carbon believed to be absorbed by the atmosphere and the oceans.

Sir John Houghton, chairman of the science working group of the Intergovernmental Panel on Climate Change, says scientists will also need to define clearly the type of forest to be included in the protocol. Questions include whether emissions from managed forests ought to form part of an anthropogenic inventory - and defining the difference between a managed and a natural forest.

Similarly, researchers will need to find an accurate method of calculating average emissions and absorption of gases per unit area over a large area of forest. The problem was neatly summarized by the chairman of the Kyoto conference, Raul Estrada Ouyela: "You can't count every Christmas tree in the world."

Several research groups have already made initial estimates of the potential impact of the protocol on global temperature trends.

Their main conclusion is that, without further action, the magnitude of emissions reductions agreed is unlikely to have a major impact on global temperature rise.

According to one climate model, if all developed countries kept to their Kyoto target of reducing emissions by 5.2 per cent from 1990 levels before 2012, world temperatures would still rise by $2.11^{\circ} \mathrm{C}$ by 2100 . This is only $0.27^{\circ} \mathrm{C}$ lower than the 'business as usual' scenario of world temperature rise if no intervention is taken. If developed countries were to stabilize their emissions at 1990 levels, global temperatures would rise by $2.15^{\circ} \mathrm{C}$ by 2100 .

The data were generated by Mike Hulme, reader in climatology at the University of East Anglia. Hulme says the temperatures indicated in his calculations may not turn out to be correct, as models are subject to many assumptions and uncertainties.

Hulme says that comparing the different sets of data is more meaningful, and thinks the change in temperature if countries adhere to the protocol will be small enough to be masked by natural changes to the Earth's climate. "That is not saying Kyoto is not important... It is an important first step that will pave the way for subsequent amendments that will dig a little deeper."

EhsanMasood

\section{Faith, hope and tact needed for US ratification}

[WASHINGTON] The Clinton administration will embark on the first stage of an uphill struggle to implement the Kyoto protocol when it presents its 1999 budget in February. Officials are this week working to incorporate into Clinton's budget proposal tax incentives for energy efficiency, as well as extra money for energy research, along lines suggested earlier in the year by the President's Council of Advisors on Science and Technology.

But getting these budget proposals through the Congress will be one of the easier steps required to bring the United States anywhere near its target of reducing greenhouse gas emissions to 7 per cent below their 1990 levels by 2012.

A major diplomatic effort will also be needed to bring the proposed trading scheme for emission permits - as well as some form of meaningful participation by developing countries - into the agreement at the next meeting of parties to the climate convention, to be held in Buenos Aires next autumn. Only then will the US administration consider seeking ratification of the final treaty in the Senate.

Senator John Kerry (Democrat, Massachusetts), a strong supporter of action to cut emissions, said last week that the protocol was not ready for ratification. He would not be drawn on when it would be ready: " don't think people should focus on ratification. We should focus on the next steps, such as the Buenos Aires meeting. We'll know when the time is right to bring this before the Senate."

Kerry points out that such timing is entirely at the discretion of the president. But he hints that the treaty may not be ratified until after 2000, when Vice-President A Gore hopes to succeed Bill Clinton. If anyone other than Gore is elected with the treaty unratified, its prospects would be extremely bleak

Short of ratification, the White House can still take some executive actions such as adjusting the government's own energy use patterns - in line with the treaty. It can also fight for, and possibly win, support for more energy research in budget negotiations with the Congress. But Senate ratification is regarded by most observers as an essential prerequisite for any break in the upward

trajectory of greenhouse gas emissions in the United States.

That is because the implementation scheme proposed by Clinton on 22 October relies heavily on emitters' faith that they will win credits when a trading scheme is introduced, scheduled for 2008 (see Nature 389, 893; 1997). If corporations have no faith that the trading scheme will come into effect, they will not invest in cutting emissions.

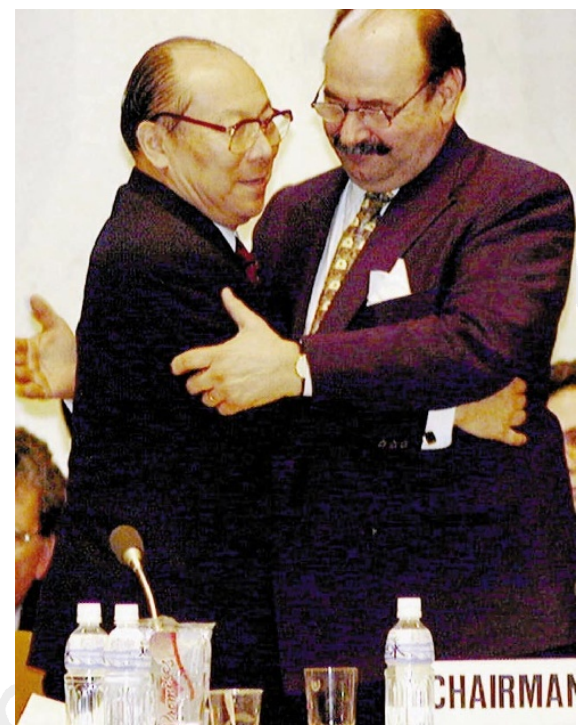

Home at last: Japan's Ohki (left) and chairman Estrada share relief at the end of the conference.

\section{Minister's near miss at the final curtain}

[TOKYO] The need to extend the final day of the Kyoto conference meant that many participants, exhausted by rounds of all-night talks, were forced to miss their flights home and negotiate without interpreters, who left as their contracts expired at midnight on 10 December. But perhaps the biggest surprise came when the president of the conference announced his resignation and walked out of the plenary session before the finale - only to withdraw his resignation an hour later.

Hiroshi Ohki, Japan's environment minister and president of the conference, resigned from his post on the morning of 11 December and hastily left the conference hall to catch a train back to Tokyo to vote in a noconfidence motion against Prime Minister Hashimoto's cabinet. Enraged members of Japanese nongovernmental organizations are said to have pursued Ohki to Kyoto station, as well as contacting members of the parliament, to stop Ohki from boarding the train.

The parliament made a last-minute arrangement to exempt Ohki from the noconfidence vote, so he was able to resume his presidency and clinch the landmark protocol for the reduction of greenhouse gases shortly after 2 p.m. that day.

Critics claimed that the incident highlighted the lack of leadership by Japan during the conference. "The fact that the prime minister tried to call Ohki back to Tokyo on the final day of the conference reflects their [the Japanese government's] degree of commitment on this issue," says Makoto Hoshino, director of the World Wide Fund for Nature in Japan. Others, however, said that Japan should share the credit for the fact that a final compromise agreement was reached between the various conflicting points of view.

Asako Saegusa 